\title{
Translation and Creative Writing: An Interview with Professor Margaret Rogers
}

\author{
Interviewed by Ruzbeh Babaee \\ Faculty of Modern Languages and Communication, Universiti Putra Malaysia
}

Received: -

doi:10.7575/aiac.ijclts.v.4n.1p.1
Accepted: -

Published: 05-01-2016

\section{Introduction}

This interview was conducted with Emerita Professor Margaret Rogers with the aim of providing a brief but informative summary of the relationship between translation and creative writing. Emerita Professor Rogers is in the Centre for Translation Studies, School of English and Languages, University of Surrey, UK. She is also the founder of Terminology Network at the Institute of Translation and Interpreting in the UK. Professor Rogers introduced creative writing into the translation curriculum some 10 years ago at her own university.

\section{The Interview}

\section{$R^{1}$ : Do you believe in a theory of translation?}

$\mathbf{M R}^{2}$ : There are many ways of trying to understand and, where we can, explain translation in all its guises, loci and times. To talk about ' $a$ theory' in this context doesn't help much. There are many different approaches to the academic study of translation: rather simply put, the particular approach which we choose to adopt may depend on our object of study (e.g. literary translation or specialised translation), what we want to find out about this (e.g. are we interested in product or process, in a historical or contemporary perspective), what resources we have available (e.g. a fully funded research team or a solo effort) and so on. Many projects are interdisciplinary — this has long been recognised—and translation scholars are becoming much more resourceful in identifying, adopting and adapting relevant approaches from intersecting disciplines such as comparative literature, cultural studies, history, linguistics, philosophy, psychology and sociology. Some scholars are now advocating a problem-based approach. In any research project it is important to establish how the problem/phenomenon/issue which has been identified as the focus of the study can be tackled. For this, in an empirical study a method is crucial: in translation studies this is rarely something that can be picked off the shelf and is often a contribution to the discipline in itself. And then, we need to find a well-motivated framework which can support an analysis — of data or arguments_leading to fresh perspectives. The same set of data or arguments can be analysed differently, depending on your objectives. Whether you can describe any of this as 'a theory', I doubt.

I would also choose a different word from 'believe': 'belief' implies faith, whereas academic work is about identifying gaps in our knowledge, selecting material, evaluating arguments and challenging perspectives. But I suppose we all need a bit of faith when we start out on a new project - faith that we are going to produce something worthwhile.

\section{RB: Do you see translation as a science or an art?}

MR: This is an old question which has been widely discussed in the past. As a dichotomy, it forces a false opposition. All translation requires an awareness of form and content, and the relations between them depending genre, translation purpose and so on.

\section{RB: What is the relationship between translation and creative writing?}

MR: Scholarly publications have largely dealt with this question from the perspective of literary translation, but any writing activity has the potential to enhance the writer's awareness of the affordances and constraints of text as a written artefact. And as translation--whatever its nature--is a type of writing, and translators are writers, then it follows that from a developmental point of view, undertaking focused creative writing exercises can potentially enhance the translator's ability to craft appropriate translation solutions. Creative writing is not only an exercise in imagination, it is also a discipline in writing for a particular purpose, as is translation. Please see Doloughan \& Rogers 2006.

\footnotetext{
${ }^{1}$ Ruzbeh Babaee

${ }^{2}$ Margaret Rogers
} 
RB: Have theories of translation any place in creative writing?

MR: My colleagues in creative writing are far better placed to answer this question. I refer you to the work of my colleague Dr Fiona Doloughan (e.g. English as a Literature in Translation, 2015).

\section{RB: Do we have creative translation?}

MR: Indeed. Of course, some translation tasks are more challenging than others, but this is often viewed in terms of literary translation being creative and specialised translation, routine and banal. This is not my view. While there is no doubt that translating many works from the literary canon, such as James Joyce's Ulysses, is highly demanding, translating Barbara Cartland's numerous popular romances is much more straightforward, reflecting the very different quality of the original writing. Similarly, in specialised translation, some texts are easier to translate than others, depending on how routine they are (established terms, stable subject matter, clear genre conventions, bland expression without culture-specific references). But even then, the translator has to establish how well source-text and sourcelanguage characteristics travel into the target-language and target-text environment. For example, a particular technology may be more advanced in one culture than the other, requiring innovative solutions for filling terminological gaps. Or a genre might not (yet) feature widely or in any well-established way in the target culture e.g. popular science writing in Arabic. So I would like to move the debate away from the literary versus 'non-literary' axis, whilst also recalling that specialised discourse in many natural sciences (e.g. biology, physics) as well as social sciences (e.g. economics, psychology) is packed full of figurative language as a way of trying to understand the world around us; not all of these linguistic expressions or indeed their underlying concepts transfer easily into another language or culture.

\section{RB: Is there a definitive translation? Can we speak of a final, absolute translation?}

MR: No. All translation is interpretive in some way. Even where established terms and phrases are in use in highly conventionalised texts, it is hard to imagine that the translator's agency is redundant. Even texts which have standard equivalents in the other language / culture, e.g. notices such as 'Beware of the dog' (French Attention, chien méchant; German Vorsicht, bissiger Hund; Italian Attenti al cane!), could be translated differently if the purpose of the translation is to inform about the structure of the source text rather than produce a notice which is functionally appropriate. The scope for variation in literary translation is, of course, even wider in many cases and not necessarily linked to a change in the purpose of the translation. Toury's Descriptive Translation Studies has shown us how important the norms of reception are and how these norms can vary according to time and place.

\section{RB: How do you deal with a term with several different shades of meaning in the original language?}

MR: Even specialist terms can be 'perspectivised' in different ways in a text, depending on which characteristics of the concept (as specified in an intensional definition, for example) are activated by the co-text. The translator's job is to establish whether there is a similar affordance for such nuancing in the target language e.g. by researching model texts with similar content and design features to those of the source text, or by communicating with experts working in the relevant field. In the latter case, however, we always need to be prepared for puzzled reactions and sometimes poor insight into actual practice. These kinds of differences are rarely recorded in codified sources such as termbases or dictionaries, as they are often highly contextualised and therefore present difficulties for the abstraction that is necessary for codification. If no immediate solution is apparent in the target language, perhaps the nuancing is not necessary or poses no problems for target-language readers. Examples of this kind of nuancing can, however, be found in Rogers $1999 ; 2007$.

\section{RB: Do you think that translation can be a rich source of scandal? Is a translator accused of malpractice?}

MR: Of course, translators have to be aware that they can get sued if they make a translation error (e.g. mistranslating a number or a key term for financial and safety reasons respectively), and that they have a responsibility towards their client and their readers, but I think you have something else in mind here.

\section{RB: What approach do you take in your translation workshops and classes?}

MR: An open discussion of the possibilities for translation, bearing in mind the purpose of the translation and the assumed expectations of target readers, even the environment in which the text is to be read or used, which might affect layout. The students' own expectations can develop in a number of ways, through pair or group work, self-reflection, comparison of their own work with published translations, identification and evaluation of resources (increasingly online). Students understandably seek security when translating, for which the notion of the 'perfect' solution would, of course, be reassuring, were it not so elusive and misleading. That is not to say, however, that there is not on occasion a correct solution e.g. a company's choice for the equivalent of a particular term, or an established standard. The overall goal is to establish through experience that the practice of translation is a decision-making process in which the translator's agency is a key feature and to guide students towards tools and resources as well as developing evaluative skills to optimise this process. In my view, additional classes shared by students from different language groups can enrich this translation pair-specific experience by providing a systematic overview of different approaches to and issues 
in translation, enabling students to develop relevant points of reference for their decisions. Sometimes these classes are called 'principles of translation', 'theory of translation', 'approaches to translation', 'translation issues' and so on.

\section{References}

Doloughan, F. (2015). English as a Literature in Translation. London: Bloomsbury Academic.

Doloughan, F. \& Rogers, M. (2006). 'Mediation and Regulation of Textual Space: the role of creative writing in translator training'. In I. Kemble and C. O'Sullivan (eds) (2006) Translation and Creativity: How creative is the translator? Proceedings of the Conference held on 12 November 2005 in Portsmouth. Portsmouth: University of Portsmouth, pp. 34-43.

Rogers, M. (1999). 'Translating Terms in Text: Holding on to Some Slippery Customers'. In: G. Anderman \& M. Rogers (eds) Word, Text, Translation. Clevedon: Multilingual Matters, pp.104-16.

Rogers, M. (2007). 'Lexical chains in technical translation: A case study in indeterminacy'. In: B. Antia (ed.) Indeterminacy in LSP and Terminology. Amsterdam/Philadelphia: John Benjamins, pp.15-35.

Rogers. M. (2015). Specialised Translation. Shedding the 'Non-Literary' Tag. Houndmills, Basingstoke, UK: Palgrave Macmillan.

Toury, G. (1995). Descriptive Translation Studies - and beyond. Amsterdam / Philadelphia: John Benjamins (Revised edition: 2012). 